\title{
Identification of Human and Rodent Thymic Epithelium Using Tetanus Toxin and Monoclonal Antibody A2B5
}

\author{
Barton F. Haynes, Kazuo Shimizu, and George S. Eisenbarth, Department of \\ Medicine, Divisions of Rheumatic and Genetic Diseases and Endocrinology, \\ and the Departments of Physiology, Microbiology, and Immunology, Duke \\ University Medical Center, Durham, North Carolina 27710
}

\begin{abstract}
A B S T R A C T Using a monoclonal antibody (A2B5), which binds to GQ ganglioside, and tetanus toxin, which binds to GD and GT gangliosides, distinct regions of human and rodent thymic epithelial cells have been identified. The lymphoid elements of the thymus do not bind A2B5 or tetanus toxin. The A2B5 and tetanus toxin-binding cells form a network of thymic epithelial cells throughout the thymic subcapsular cortex and thymic medulla and contain thymopoietin and thymosin $\alpha-1$.
\end{abstract}

\section{INTRODUCTION}

The thymus plays a central role in the differentiation of $\mathrm{T}$ lymphocytes (1). Lymphocytes in various stages of maturation are found throughout the thymic cortex and medulla; however, only a minority of thymic lymphocytes mature completely and migrate to peripheral lymphoid organs $(2,3)$. Thymic epithelial cells are in intimate contact with thymic lymphocytes and as well, produce thymic hormones such as thymopoietin and thymosin $\alpha-1$ (4-6).

Eisenbarth et al. have recently characterized a murine monoclonal antibody (A2B5) that reacts with a complex neuronal GQ ganglioside expressed on the cell surface of neurons, neural crest-derived cells, and peptide-secreting endocrine cells (7-9). Tetanus toxin (TT), ${ }^{1}$ which binds to GD and GT gangliosides (10), also binds to this neuroendocrine family of cell types (8). These observations, coupled with previous studies

\footnotetext{
Address reprint requests to Dr. B. F. Haynes, Duke University Medical Center, Durham, NC 27710.

Received for publication 8 February 1982 and in revised form 8 June 1982.

${ }^{1}$ Abbreviations used in this paper: FITC, fluorescein isothiocyanate; MG, myasthenia gravis; RITC, rhodamine iso-
} thiocyanate; TT, tetanus toxin. demonstrating that a portion of thymic epithelium in fowl is neural crest derived (11), led us to determine if antibody A2B5 and/or TT bound to cells in human and rodent thymus. In this study, we demonstrate that human and rodent thymic epithelial cells express antigens recognized by antibody $\mathrm{A} 2 \mathrm{~B} 5$ and as well bind TT. A2B5 ${ }^{+}$and $\mathrm{TT}^{+}$thymic epithelial cells are found in two discrete locations-the subcapsular cortex and medulla. Moreover, using monoclonal antibody A2B5 and rabbit antithymopoietin or antithymosin $\alpha-1$ antibodies, we showed that $\mathrm{A}^{2} \mathrm{~B}^{+}, \mathrm{TT}^{+}$thymic epithelial cells contain thymopoietin and thymosin $\alpha-1$.

\section{METHODS}

Thymic tissue procurement and processing. Human thymus tissue was obtained from six normal adolescents at the time of corrective cardiovascular surgery for congenital heart disease, and three adult myasthenia gravis (MG) patients at the time of therapeutic thymectomy. The pathologic diagnosis in all three MG thymuses was thymic hyperplasia. Rodent thymus tissue was obtained from three BB Wistar female 2-mo-old rats and three BALB/c female 6-wk-old mice. Portions of human thymus were gently dissociated from thymic stroma using curved forceps; chunks of tissue were removed by passing the cell suspension through a gauze sponge (12). Cytocentrifuge preparations were made, stained with Wright's stain, and counted under light microscopy for cell differential. Normal human thymus cell suspensions contained (mean \pm SEM) $90 \pm 1 \%$ small lymphocytes, $8 \pm 3 \%$ large lymphocytes, $1 \pm 0.75 \%$ monocytes, and $0.3 \pm 0.5 \%$ eosinophils. Fresh human, murine, and rat thymus was snap frozen in an ethanol-dry ice slurry, embedded in OCT compound (Scientific Products, McGraw Park, IL), and 4- $\mu \mathrm{m}$ frozen sections were cut, fixed $10 \mathrm{~min}$ in cold acetone, and stored frozen at $-100^{\circ} \mathrm{C}$. Acetone-fixed thymus tissue slides were incubated for $30 \mathrm{~min}$ in a moist chamber with a saturating amount of monoclonal antibody. After three rinses with cold phosphate-buffered saline (PBS), a saturating amount (1:100 final dilution) of affinity-pure fluorescein isothiocyanate (FITC)-conjugated (fluorescein/protein ratio 6.0) goat anti- 
mouse IgG (Tago, Inc., Burlingame, CA) was layered on the slide. Following three rinses in PBS, the slides were briefly dipped in distilled water, allowed to air dry, overlayed with $30 \%$ glycerol in PBS, coverslipped, and then read on a Nikon Optiphot fluorescent microscope (13). In each experiment, background staining with comparable dilutions of P3 $\times 63$ ascites fluid and FITC-conjugated goat anti-mouse IgG was low with thymic lymphoid elements and epithelial elements (including Hassall's corpuscles) nonfluorescent.

Double indirect immunofluorescence with antithymic hormone antisera and monoclonal antibody A2B5. For determination of the simultaneous presence of thymopoietin or thymosin $\alpha-1$ and A2B5 reactivity in thymic epithelia cells, $4-\mu \mathrm{m}$ acetone-fixed frozen sections of human thymus from two normal subjects were incubated with a $1: 10$ dilution of rabbit antithymopoietin (14) (the gift of Dr. G. Goldstein, Ortho Pharmaceutical, Raritan, $\mathrm{NJ}$ ) or antithymosin $\alpha-1$ (15) (the gift of Dr. A. L. Goldstein, George Washington University, Wash. D.C.) antiserum for $30 \mathrm{~min}$ at $25^{\circ} \mathrm{C}$, washed in cold PBS three times and then incubated with rhodamine isothiocyanate (RITC)-conjugated goat anti-rabbit IgG (Tago, Inc.) for $30 \mathrm{~min}$ at $25^{\circ} \mathrm{C}$. After three washes in PBS, the thymus section was stained using antibody A2B5 and FITC-conjugated goat anti-mouse IgG as outlined above.

Controls for simultaneous antithymopoietin or antithymosin $\alpha-1$ and A2B5 reactivity included thymus sections incubated with (a) normal rabbit serum (NRS) RITC-conjugated goat anti-rabbit IgG, FITC-conjugated goat antimouse IgG; (b) NRS, RITC-conjugated goat anti-rabbit IgG, P3 $\times 63$ ascites (1:100 dilution), FITC-conjugated goat antimouse IgG and $(c)$ antithymopoietin or antithymosin $\alpha-1$, RITC-conjugated goat anti-rabbit IgG, P3 × 63 (1:100) dilution FITC-conjugated goat anti-mouse IgG.

Assay for TT binding to thymus. Rat and human thymus sections were also incubated with purified TT (kindly supplied by $R$. O. Thomsen of the Wellcome Research Laboratories, England), $0.1 \mu \mathrm{g} / \mathrm{ml}$ diluted in PBS $1 \%$ albumin for $30 \mathrm{~min}$ at room temperature, washed three times with PBS, incubated with 1:100 dilution of monoclonal anti-TT antibodies 3D8 and 3B3 (kindly supplied by V. R. Zurawski of Centocor, Inc., Malvern, PA), washed three times and then incubated as described above for antibody A2B5 with FITCconjugated anti-mouse IgG $(8,9)$.

Chloroform/methanol extraction or neuraminidase treatment of thymus tissue frozen sections. In some experiments, antibody A2B5 reactivity or TT binding to human thymus was determined before and after chloroform/methanol $(2: 1 \mathrm{vol} / \mathrm{vol})$ extraction of frozen sections of thymus tissue or after digestion of thymus sections with neuraminidase $(10 \mathrm{IU} / \mathrm{ml})$ (7) (type V, Sigma Chemical Co., St. Louis, $\mathrm{MO}$ ) for $45 \mathrm{~min}$ at $37^{\circ} \mathrm{C}$, in $\mathrm{PBS}$ pH 5.5.

\section{RESULTS}

Monoclonal antibody A2B5 showed a similar pattern of reactivity with all human, rat, and mouse thymus sections tested (Fig. 1A). Thymic medullary areas reacted strongly with A2B5 and demonstrated a dense reticular network of epithelial cells (Fig. 1B). These $\mathrm{A} 2 \mathrm{~B}^{+}$processes went up to and surrounded Hassall's corpuscles, but the central areas of Hassall's corpuscles were unreactive with A2B5. As seen in Fig. 1C, rat thymic medulla also showed a similar pattern of reactivity with A2B5. In the thymic cortex, many areas were completely nonreactive with A2B5 with only a few scattered $\mathrm{A} 2 \mathrm{~B} 5^{+}$cells seen. However, epithelial cells in the subcapsular cortex area of normal human thymus stained strongly with A2B5 in a pattern similar to that seen in the thymic medulla (Fig. 1D). In no areas of the thymus did A2B5 show rim staining of thymocytes. In addition, single cell suspensions (consisting of lymphocytes) of six normal and three MG thymuses were studied for the expression of antibody A2B5 receptors using indirect fluorescence (13). Whereas in each thymus we had previously seen that A2B5 reacted strongly with large portions of the thymus, only $3.6 \pm 1.1 \%$ (mean \pm SEM) of the thymocytes were $\mathrm{A} 2 \mathrm{~B}^{+}$, a number consistent with epithelial cell contamination of the preparation. In contrast, $97 \pm 2 \%$ (mean \pm SEM) of thymocytes were reactive with monoclonal antibody $3 \mathrm{Al}$, a reagent previously shown to bind to the majority of human intrathymic lymphocytes (16).

To provide supportive evidence that antibody A2B5 binding in the thymus was via ganglioside molecules similar to those found in other $\mathrm{A} 2 \mathrm{~B}^{+}$neuroendocrine tissues (7-10), A2B5 reactivity and TT binding to human thymus was determined before and following chloroform/methanol (2:1) extraction of frozen sections of thymus tissue or following digestion of frozen thymus sections with neuraminidase. We found that chloroform/methanol extraction or neuraminidase treatment completely removed thymic A2B5 and TT binding, whereas the glycoprotein antigen $3 \mathrm{Al}$ (16) was unaffected by neuraminidase treatment or chloroform/methanol extraction.

To determine if other components of the human hematopoietic system reacted with antibody A2B5, acetone-fixed frozen sections from a large number of human tissues were tested for A2B5 reactivity. We found normal lymph nodes (two subjects), normal adult spleen (one subject), normal fetal spleen (one subject), normal adult liver (one subject), and normal fetal liver (one subject) did not contain A2B5 reactive components. However, the squamous epithelial basal cell layer in tonsil (two subjects), and the basal epithelial cell layer in skin biopsy sections from three cutaneous $T$-cell lymphoma patients and two normal subjects did react with A2B5. Thus, nonthymic lymphoid tissue has been reported to secrete thymopoietinlike factors $(17,18)$, and regarding lym phoid tissue, both thymic and tonsil epithelium reacted with antibody A2B5.

To correlate A2B5 reactivity with the endocrine function of the thymus, labeling of thymic epithelium with rabbit antithymopoietin (14) or rabbit antithymosin $\alpha-1$ (15) + RITC-conjugated goat anti-rabbit IgG followed by A2B5 + FITC-conjugated goat antimouse IgG was performed (Fig. $2 \mathrm{~A}$ and $2 \mathrm{~B}$ ). We found essentially a 1:1 correlation of A2B5 reactivity (Fig. 

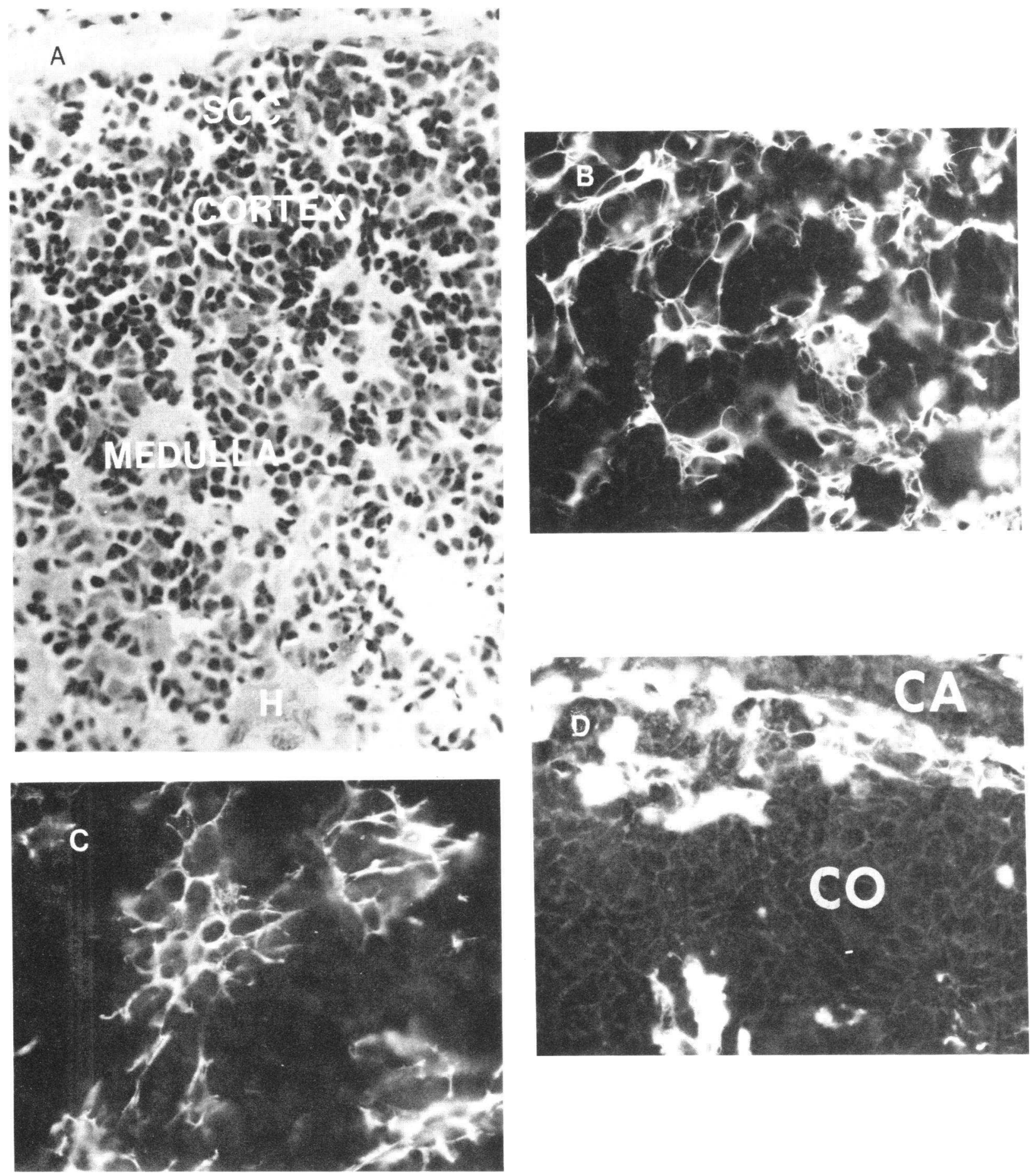

FigURE 1 Binding pattern of monoclonal antibody A2B5 to normal human and rodent thymus. (A) Light micrograph demonstrating regions of a normal thymus lobule. From top to bottom are the fibrous capsule of the thymic lobule, the subcapsular (SCC) region of the cortex, the cortex proper, and the medulla. $H$ denotes a Hassall's corpuscle (hematoxylin and eosin stain, $\times 400$ ). (B) A2B5 in normal human thymus medulla stained cells in a reticular pattern. This pattern was seen in six normal thymuses and in three MG thymuses. $(\times 400)$. (C) A2B5 in normal rat thymus medulla showed a pattern of reactivity identical to that seen in human thymic medulla. Similar reactivity pattern was seen on all mouse thymuses $(\times 400)$. (D) Human thymic cortex showing A2B5 reacting strongly in subcapsular cortex zones, between the thymic capsule (CA) and thymic cortical lymphocytes (CO). All cortical lymphocytes were nonreactive with antibody A2B5 (×400). 

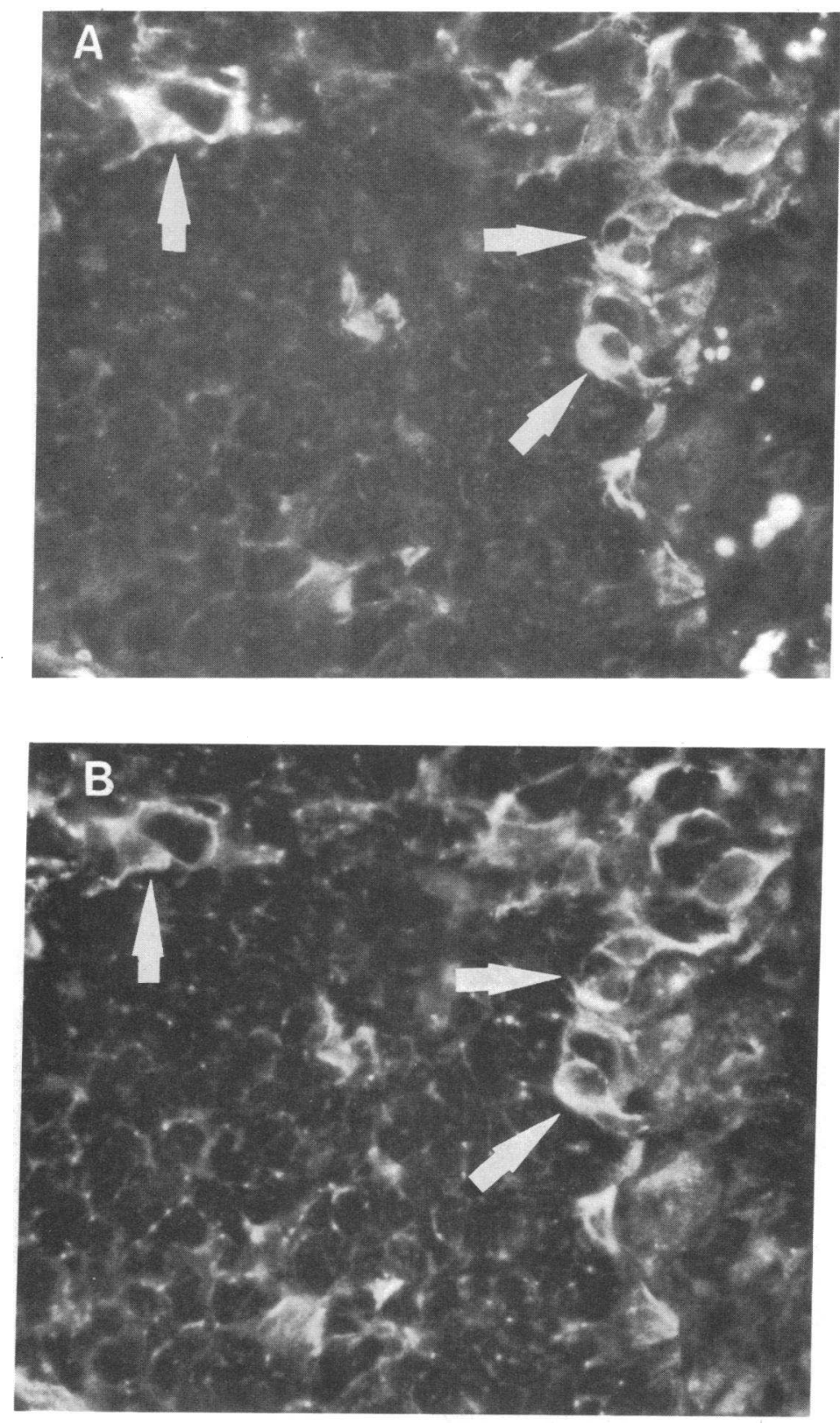

FIGURE 2 A2B5 reactive thymic epithelial cells contain thymopoietin. (A) Using filters for fluorescein excitation ( $515 \mathrm{~W}$, B Nikon) $\mathrm{A}^{2} \mathrm{~B}^{+}$thymic medullary epithelial cells fluoresce brightly (arrows). (B) Using filters for rhodamine excitation (580W, G Nikon), the same cells that were $\mathrm{A}^{2} \mathrm{B5}^{+}$are seen to be strongly positive for thymopoietin (arrows) $(\times 400)$.

2A) with bright antithymopoietin staining (Fig. 2B) or antithymosin $\alpha-1$ (data not shown). These experiments were repeated on six thymus specimens with the same results each time. Some other epithelial cells of thymic cortex occasionally appeared to be reactive with antithymopoietin or antithymosin $\alpha$-1 but not with A2B5, but clearly all $\mathrm{A} 2 \mathrm{~B} 5^{+}$cells reacted either with the antithymopoietin or antithymosin $\alpha-1$ antibodies.

Because all neuroendocrine cell types that we have studied bound antibody A2B5 and also bound TT (8, 9 ), using indirect immunofluorescence with monoclonal anti-TT antibodies we studied TT binding to thymus tissue. We found that TT bound to sections of 
rat and human thymus in a pattern identical to antibody A2B5 (Fig. 3A and 3B).

\section{DISCUSSION}

Monoclonal antibody A2B5 reacts with a glycolipid of neurons with the solubility and chromatographic properties of GQ ganglioside (7). In a similar manner, TT reacts with cell surface complex GD and GT gangliosides (10). Receptors for both of these molecules were initially detected on neurons, but Eisenbarth et al. recently discovered that peptide-secreting endocrine cells, often derived from the neural crest, also react with antibody A2B5 and bind TT $(8,9)$. In this study we have shown that two major regions of thymic epithelium-the subcapsular cortex and the medullareact with antibody A2B5 and TT. In addition, we have shown $\mathrm{A} 2 \mathrm{~B}^{+}$, TT-binding thymus epithelial cells contain thymopoietin and thymosin $\alpha-1$.

Recent studies by Hirokawa et al. (15), Ritter et al. (19), and Goldstein et al. (20) have suggested that normal human thymic epithelium exists in two regionsthe subcapsular cortex and the medulla. Ritter et al. (19) demonstrated that human subcapsular cortical thymic epithelium expresses Thy-l antigen while medullary thymic epithelium does not. Hirokawa et al. (15) and Goldstein et al. (20) demonstrated that the thymosin $\alpha$-1-containing thymic epithelium is ar- ranged in two areas-the subcapsular cortex and the medulla. In contrast, thymosin $\beta-3$, another thymusderived polypeptide, is present only in the subcapsular cortical epithelial region and not the medullary epithelial region. Additional evidence for antigenically distinct regions of the endocrine thymic epithelium comes from the observation of Hirokawa et al. (15) that during aging, the medullary thymosin $\alpha$-l-containing epithelial cells atrophy, while the subcapsular cortical epithelial cells do not. Our studies confirm the thymosin $\alpha-1$ localization to the subcapsular cortex and medullary thymic epithelium and demonstrate a similar intrathymic location for thymopoietin. Moreover, we show that those similar to other neuroendocrine tissues, thymic epithelial cells bind TT and monoclonal antibody A2B5. Although the ganglioside nature of thymic epithelial cell receptors for TT and antibody A2B5 have not been directly proven in our study, that these probes bind to GD, GT, and GQ gangliosides on neuronal tissues has been previously demonstrated (710). That chloroform/methanol extraction and neuraminidase treatment abrogates A2B5 and TT binding to thymus epithelium is only suggestive and not definitive evidence for the glycolipid nature of these receptors in thymus.

All of the cells belonging to the amine precursor uptake and decarboxylation (APUD) series of cells
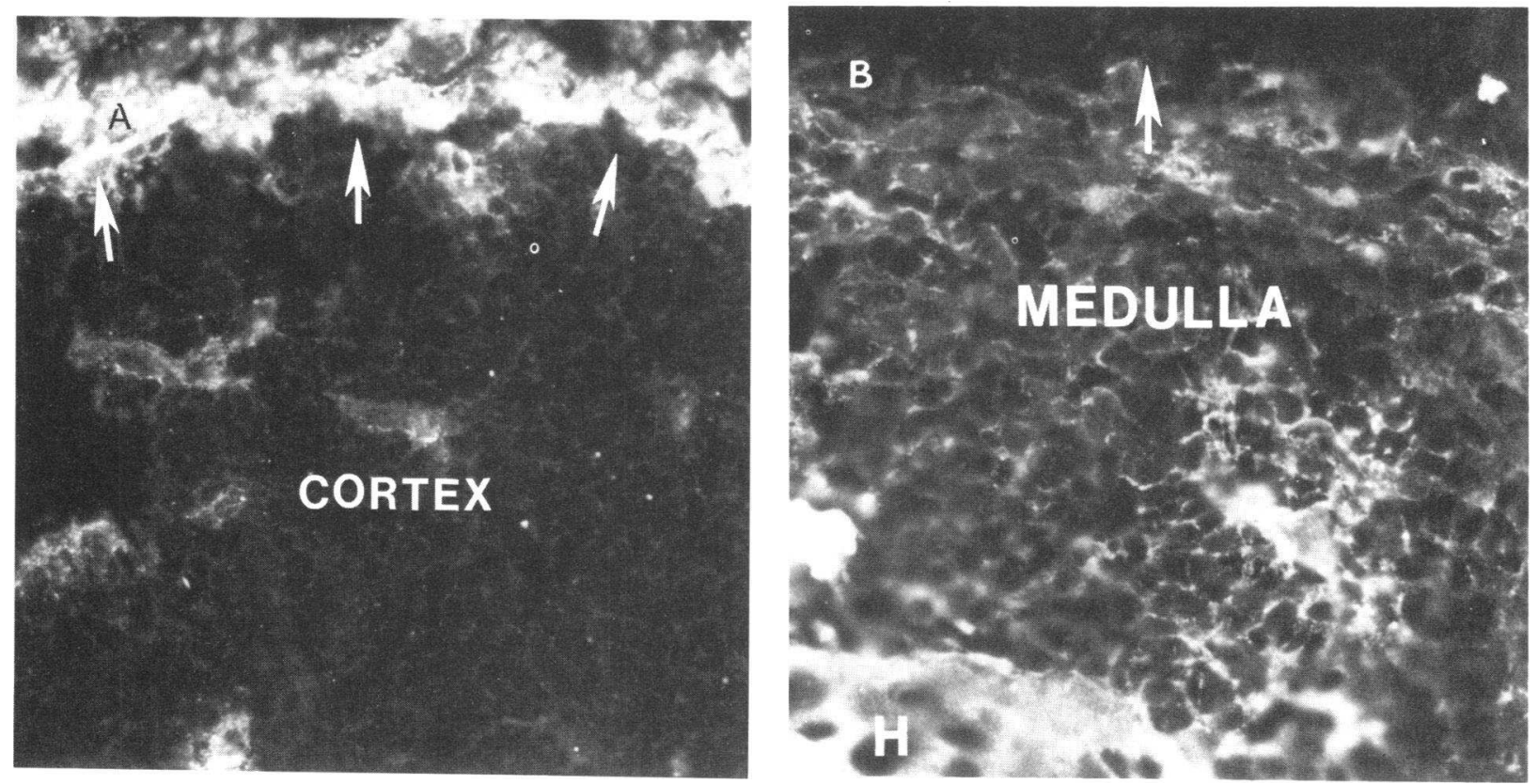

FIGURE 3 Pattern of TT binding to normal human thymus using indirect immunofluorescence. (A) Subcapsular cortical (arrows) and cortical region of normal human thymus showing TT reactive subcapsular cortex and negative cortical zone $(\times 400)$. (B) Medullary thymic epithelium was strongly TT reactive with negative cortical zone seen at top of photomicrograph. TTpositive Hassall's corpuscle $(\mathrm{H})$ is seen $(\times 400)$. 
previously studied including pancreatic islet cells, anterior pituitary cells, adrenal medullary carcinomas of the thyroid, melanomas, and neuroblastomas reacted with antibody A2B5 and TT (8). Similar to the recent studies of neuron-specific enolase, a series of nonneuronal APUD cells have been found to express what was initially considered neuronal antigens $(21)$. Though the majority of cells reacting with antibody A2B5 are of neural crest derivation, not all $\mathrm{A}^{\mathrm{B}} 5^{+}$cells derive from the neural crest. In particular, pancreatic islet cells may not be of neural crest origin $(11,22,23)$, yet these cells and their tumors bind antibody A2B5 and TT $(8,9)$. The expression of complex gangliosides by cells, therefore, may reflect a common (endocrine) function rather than common embryonic derivation.

The function of surface complex gangliosides on neuroendocrine cells is at present unknown. The unlimited quantities of monoclonal antibody A2B5 available should facilitate studies of the function of these molecules, and most importantly, allow the isolation of thymic epithelial cells reacting with antibody A2B5. A cell surface marker for the endocrine cells of the thymus will undoubtedly facilitate studies of the role of these cells in the differentiation of $T$ lymphocytes and in studies of human immunodeficiency diseases.

\section{ACKNOWLEDGMENTS}

The authors thank Drs. R. Metzgar, A. Roses, and C. W Olanow for thymic tissue, Dr. R. Snyderman and Dr. R. Metzgar for critical review of the manuscript, Ms. Lucinda Hensley and Richard Scearce for expert technical assistance, and Ms. Joyce Lowery and Ms. Bobbie Williams for expert secretarial assistance.

This work was supported in part by grant CA 28936 from the National Institutes of Health. Dr. Eisenbarth is a recipient of a Basil O'Connor starter grant from the National Foundation and a Career Development Award from the Juvenile Diabetes Foundation. Dr. Haynes is the recipient of a Research Career Development Award K04-CA00695 from the National Institutes of Health.

\section{REFERENCES}

1. Cantor, H., and I. Weissman, 1976. Development and function of subpopulations of thymocytes and T lymphocytes. Prog. Allergy. 20: 1-64.

2. Matsuyama, M., M. N. Wiadrowski, and D. Metcalf. 1966. Autoradiographic analysis of lymphopoiesis and lymphocyte migration in mice bearing multiple thymus grafts. J. Exp. Med. 123: 559-576.

3. McPhee, D., J. Pye, and K. Shortman. 1979. The differentiation of $T$ lymphocytes. V. Evidence for intrathymic death of most thymocytes. Thymus. 1: 151-162.

4. Wekerle, H., U. Ketelsen, and M. Erust. 1980. Thymic nurse cells. Lymphoepithelial cell complexes in murine thymuses: morphological and serological characterization. J. Exp. Med. 151: 925-944.

5. Wekerle, H., and U. Ketelsen. 1980. Thymic nurse cells-la bearing epithelium involved in $\mathrm{T}$-lymphocyte differentiation? Nature (Lond.). 283: 402-404.

6. Bach, J. F., and G. Goldstein. 1980. Newer concepts of thymic hormones. Thymus. 2: 1-4.
7. Eisenbarth, G. S., F. S. Walsh, and M. Nirenberg. 1979. Monoclonal antibody to a plasma membrane antigen of neurons. Proc. Natl. Acad. Sci. USA. 76: 4913-4917.

8. Eisenbarth, G. S., K. Shimizu, M. Conn, B. Mittler, and S. Wells. 1981. Monoclonal antibody F12 A2B5: expression on neuronal and endocrine cells. In Monoclonal Antibodies to Neural Antigens. Cold Spring Harbor Symposium. 209-218.

9. Eisenbarth, G. S., K. Shimizu, M. A. Bowring, and S. Wells. 1982. Expression of receptors for tetanus toxin and monoclonal antibody A2B5 by pancreatic islet cells. Proc. Natl. Acad. Sci. USA. 79: 5066-5070.

10. Leeden, R. W., and J. Mallanby. 1977. Gangliosides as receptors for bacterial toxins. In Perspectives in Toxicology. A. Bernheimer, editor. John Wiley \& Sons, Inc., New York. 15-42.

11. Dourain, N. M., and F. V. Jotereau. 1975. Tracing of cells of the avian thymus through embryonic life in interspecific chimeras. J. Exp. Med. 142: 17-40.

12. Haynes, B. F., and A. S. Fauci. 1977. Activation of human B lymphocytes. III. Concanavalin A-induced generation of suppressor cells of the plaque-forming cell response of normal human B lymphocytes. J. Immunol. 118: 2281-2287.

13. Haynes B. F., L. L. Hensley, and B. V. Jegasothy. 1982. Differentiation of human T lymphocytes: II. Phenotypic difference in skin and blood malignant $T$ cells in cutaneous T-cell lymphoma. J. Invest. Dermatol. 78: 323326.

14. Goldstein, G. 1976. Radioimmunoassay for thymopoietin. J. Immunol. 117: 690-692.

15. Hirokawa, K., J. E. McClure, and A. L. Goldstein. 1982. Age-related changes in localization of thymosin in human thymus. Thymus. 4: 19-29.

16. Haynes, B. F. 1981. Human T-lymphocyte antigens as defined by monoclonal antibodies. Immunol. Rev. 57: 126-161.

17. Safia, B., R. A. Good, J. J. Twomey, V. Lewis, and G. Goldstein. 1979. A novel lymphocyte differentiating factor in serum of patients with mycosis fungoides and Sezary syndrome. Blood. 54: 837-841.

18. Oosterom, R., L. Kater, and L. H. P. Rademaker. 1981. How unique is the thymus? Conditioned media from thymus and tonsil epithelial cultures share biological activities in T-cell maturation. Clin. Immunol. Immunopathol. 19: 428-436.

19. Ritter, M. A., C. A. Sauvage, and S. F. Cotmore. 1981. The human thymus microenvironment: in vivo identification of thymic nurse cells and other antigenically distinct subpopulations of epithelial cells. Immunology. 44: 439-446.

20. Goldstein, A. L., T. K. Low, G. B. Thurman, M. M. Zatz, N. Hall, J. Chen, S. K. Hu, P. B. Naylor, and J. E. McClure. 1981. Current status of thymosin and other hormones of the thymus gland. Recent Prog. Horm. Res. 37: 369-415

21. Tapia, F. J., A. J. A. Barbosa, P. J. Marangos, J. M. Polak, S. R. Bloom, C. Dermody, and A. G. E. Pearse. 1981. Neuron-specific enolase is produced by neuroendocrine tumours. Lancet. I: 808-811.

22. Kissel, P., J. M. Andrea, and A. Jacquier. 1981. The endocrine cells of the thymus. In The Neurocristophathies. Masson Publishing USA, Inc., New York. 131-134.

23. Pictet, R. L., L. B. Rall, P. Phelps, and W. J. Rutter. 1976. The neural crest and the origin of the insulin-producing and other gastrointestinal hormone-producing cells. Science (Wash. DC). 191: 191-192. 